\title{
Logistics as a factor of increasing competitiveness of a company
}

\author{
Vera Baginova ${ }^{1, *}$ and Lev Fedorov ${ }^{1}$ \\ ${ }^{1}$ Russian University of Transport (Moscow Institute of Railway Engineers (MIIT), 9 Obraztsova St., \\ Building 9, 127994, Moscow, Russia.
}

\begin{abstract}
The role of cost theory in the formation of logistics systems is considered. The stages of the formation of the concept of logistics, the principles of cost analysis, and methodological approaches to minimize the costs of the process of product distribution are identified. The main reasons restraining the development of logistics in Russia are revealed. Much attention is paid to methods of calculating logistics costs. The influence of logistics on the ratio of profit and invested capital is shown.
\end{abstract}

\section{Introduction}

Considering logistics as a factor of increasing competitiveness, it must be borne in mind that the results of the implementation of logistic management decisions affect the functional costs of commodity movement and income from the sale of goods. In this regard, the task of finding the method that most adequately reflects the logistics costs in the supply chain of goods and identifying indicators showing the relationship of logistics with the main economic and financial indicators of companies is being actualized.

The development of logistic concepts represents the role of cost theory in the formation of logistic systems. In developed countries, even at the first stage of the development of the logistics concept, the so-called "decade of conceptualization" (1956 - 1965), the basis of the theory of logistics was the principle of the obligatory cost analysis and optimization of distribution channels of cargo flows (a comprehensive solution to tasks associated with the location of warehouses, determination of the optimal value of the consignment of goods and optimal routes for transportation of goods). In the future, at the stage of "testing the theory of the logistic concept" (1966 - 1970), many comprehensive studies of the activities of various economic systems were carried out. This has delivered benefits in the form of developing methodological approaches to minimizing the costs of the product distribution process. The essence of such approaches was a cross-cutting costing (the principle of "one umbrella" or "analysis of total costs") of the entire process of product distribution, taking into account mutual concessions (a kind of "victims") of its participants in order to achieve a synergetic effect.

\section{Materials and methods}

\footnotetext{
${ }^{*}$ Corresponding author: vvbaginova@gmail.com
} 
Thus, finding a balance of interests between all subjects of the goods distribution process, logistics helps to increase profits, improve the quality of customer service, and, as a result, increase the competitiveness of companies. Nowadays, in developed countries, not one of the companies with a stable market position can do without the use of logistic tools and taking into account the logistic factor in the development of both a common market strategy and specific projects.

In the Russian Federation, the sphere of production, circulation and consumption at the micro level is still not sufficiently coordinated in many cases, incurring significant losses, including in the form of lost profits. The main reasons that hinder the recognition of the interconnectedness and interdependence between the functional areas of the goods movement system in our country are:

- insufficient use of a systematic approach in the managerial activities of the management of many companies;

- the orientation of company management mainly on market management, simplistically understanding it as the process taking place under the slogan "let it go as it goes";

- the lack of vision among company management of such market flaws as the inconsistency in time of the action of supply and demand factors, as well as the degree to which sellers of goods do not recognize the needs of buyers;

- the uncertainty of management in state and public regulation as a means of optimization, operating under the motto "competition wherever possible, regulation wherever necessary";

- unwillingness of the participants in the supply chain of goods to mutually provide information about their costs, fearing to disclose a "trade secret".

However, we note that under the influence of the experience of successfully functioning domestic and foreign companies in the logistics services market, the demand for a logistics concept in Russia began to grow, albeit at a slow pace.

A systematic approach to streaming flows, in particular, flowing in the supply chain of goods, contributed to the emergence of integrated logistics, the functions of which went beyond the boundaries of one enterprise and covered the horizontal connections of the enterprises adjacent to the supply chain of goods. The principle of "maximum approach to the consumer" began to correspond to such relations, which meant the inclusion of participants in the supply chain in the system of customer preferences and the fulfillment of his requirements - to deliver material values agreed upon in quantity and quality at the agreed time and place at competitive prices, tariffs or expenses. As a result of all this, the functional approach to cost analysis has ceased to satisfy the requirements of the clientele [6.8].

Therefore, the calculation of logistic costs began to be carried out not only according to the functional principle, but at the same time by the principle of "goals" ("missions", "requirements"), which should be achieved by the logistic system within the framework of a specific "product-market" situation.

One of the basic principles of calculating logistics costs for missions was the requirement of mandatory crossing of the costs of the mission of the traditional functional boundaries. [1,2,3] At the same time, the costs of missions and functions should be consistent with each other. Fulfillment of this requirement makes it possible not only to separately analyze costs and revenues by type of consumer and market segment or distribution channel, but also to eliminate the danger of hiding significant deviations of average functional costs from specific mission costs. However, mission costing has still not found proper application, since the reflection of the costs of functions and missions in the financial statements entails significant costs. 
Thus, the main advantage of the method of calculating costs by the principle of "missions" is that it allows determining the specific costs that arise in connection with the orientation of the logistics system to customer preferences and making managerial decisions that increase the efficiency of their service. At the same time, considering logistics as a factor in increasing the competitiveness of companies, it should be noted that the choice of decisions is not possible without finding a way to control costs and indicators that most correctly reflect the relationship of logistics with the main economic and financial indicators of companies.

It is very difficult to determine the quantitative parameters of the consequences or results of decisions made. This can only be done when the following conditions are met:

- $\quad$ there is a well-functioning accounting and information system;

- a comprehensive analysis of the costs and revenues of the structural divisions of companies and all participants in the logistics chain is made on the basis of the application of the principle of "missions" and a single methodology for calculating costs;

- the share of profit from logistics activities in the total profit of companies participating in the supply chain of goods is determined.

In companies that have adopted the logistics concept, it is possible, with a sufficient degree of conditionality, to determine the impact of logistics on the ratio of profit and invested capital (fixed and working capital) used to obtain it (fig.1) [4,5,7]:

$$
P I C=\frac{\text { Sales profit }}{\text { Cost of sales }} \times \frac{\text { Cost of sales }}{\text { Invested capital }} \times 100 \% .
$$

Fig.1. Impact of logistics on the ratio of profit and invested capital.

This approach is quite acceptable, since the logistics activities of companies concern both capital groups. Firstly, the cost of elements of the logistics system, such as vehicles, loading and unloading mechanisms, warehouses and others, if they belong to the company, are part of its fixed capital. Secondly, logistic operations and flow management decisions are most closely associated with various stocks, accounts receivable and cash, which are nothing more than working capital. It should be noted that many companies, taking into account the costs of storing stocks and paying tariffs, do not single out a separate line for the costs associated with the time spent in warehouses and in transit, i.e. so-called lost profits.

\section{Results}

From the above analysis of the formation of the logistics concept and methodological approaches to assessing logistics costs, it follows that in improving the coordination of the areas of production, circulation and consumption, the fulfillment of the following two conditions is of great importance: the application of a systematic approach to the relationships of participants in the goods distribution process and compliance with the necessary proportions of market and state regulation. The misunderstanding of this by the management of many companies operating in the Russian market of logistics services, as noted above, hinders the development of logistics to a large extent. In order to eliminate such a drawback, in our opinion, it is advisable to organize advanced training courses or other forms of training for company personnel on advanced methods of goods distribution management. 
We also consider it appropriate to establish a more in-depth study of systems theory and economic theory at the relevant faculties of universities, and recommend that bodies related to the higher education system more closely link competencies in the work programs of the disciplines in logistics with the essence of the logistics concept.

The transition to horizontal connections in the goods distribution system in accordance with the principle of "approaching the consumer", as already noted, entailed a change in approaches to assessing logistics costs, i.e. the need for their calculation not only by functional areas, but also by missions. In this regard, experts in the sphere of commodity movement faced two tasks, without which it is impossible to achieve an increase in the efficiency of logistics. The solution of the first problem requires the introduction of primary reporting documentation into the practice of companies, reflecting the logistics costs of logistics functions and missions. The solution to the second problem requires the allocation in the structure of logistics costs of expenses associated with the time of storage of goods in stocks and the duration of the commodity weight along its route to consumers. The indicated types of expenses should be considered as lost profits (losses from the immobilization of funds) and determined using the interest rate on capital.

\section{References}

1. V.V. Baginova, L.B. Mirotin, L.S. Fedorov, S.B. Levin, Transport logistics (Logistic management in transport, 2018)

2. L.S. Fedorov, D.V. Kuzmin, S.B. Levin, E.A. Sysoeva, Methodological and practical aspects of the effective work of logistics (2018)

3. V.V. Baginova, Yu.M. Nerush, L.S. Fedorov, Strategy and tactics of logistics business (2018)

4. L.B. Mirotin, V.V. Baginova, L.S Fedorov, Evolutionary laws of logistics, World of Transport 15, 3 (70), 56-62 (2017)

5. L.B. Mirotin, V.V. Baginova, L.S. Fedorov, V.N. Morozov, V.I. Apatsev, Logistics methods as a management efficiency factor, Competitiveness in the global world: economics, science, technologies 2-3 (31), 91-98 (2017)

6. V.V. Baginova, L.S. Fedorov, E.A. Sysoeva, Logistics Monograph (2016)

7. V.V. Baginova, L.S. Fedorov, S.B. Levin, Harmonization of inter-resources as a methodological basis for logistics, Scientific Herald of the Moscow State Technical University of Civil Aviation 216 (6), 147-150 (2015)

8. V.V. Baginova, L.S. Fedorov, S.B. Levin, Logistic business: harmony of costs and results, World of Transport 12, 5 (54), 112-115 (2014) 